\title{
Probing Voltage Drop Variations in Graphene with Photoelectron Spectroscopy
}

\author{
Coskun Kocabas ${ }^{*} \dagger$ and Sefik Suzer* ${ }^{\dagger}$ \\ ${ }^{\dagger}$ Department of Physics and ${ }^{\ddagger}$ Department of Chemistry, Bilkent University, Ankara 06800, Turkey
}

Supporting Information
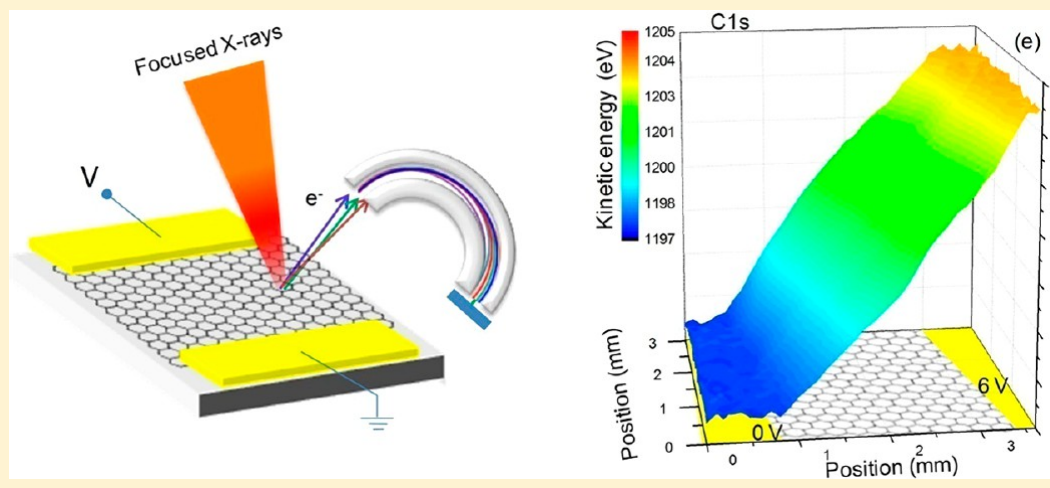

ABSTRACT: We use X-ray photoelectron spectroscopy (XPS) for characterization of voltage drop variations of large area single-layer graphene on quartz substrates, by application of a voltage bias across two gold electrodes deposited on top. By monitoring the spatial variation of the kinetic energies of emitted C1s photoelectrons, we extract voltage variations in the graphene layer in a chemically specific format. The potential drop is uniform across the entire layer in the pristine sample but is not uniform in the oxidized one, due to cracks and/or morphological defects created during the oxidation process. This new way of data gathering reintroduces XPS as a major analytical tool for extracting electrical as well as chemical information about surface and/or nanostructured materials.

\begin{abstract}
$S_{\text {vides }}^{\text {vol }}$ ynthesis of free-standing two-dimensional crystals ${ }^{1}$ provides new opportunities to study fundamental science in reduced dimensions ${ }^{2}$ as well as to develop new technologies. ${ }^{3}$ Particularly, graphene is at the center because of its unique electronic and mechanical properties. Extremely high charge mobility ${ }^{4}$ and optical transparency ${ }^{5}$ together with the ability to be synthesized over large areas ${ }^{6}$ makes graphene a promising material as a high performance semiconductor and a transparent conducting film. These applications require electrical characterization of graphene at different length scales. Besides electrical characterization, chemical characterization is essential to monitor and control dopants/defects in graphene. Characterization tools that provide simultaneous electrical and chemical analysis are desirable to understand the ultimate limits as well as performance of graphene-based devices.

Photon-based spectroscopic techniques, like UV-vis, Raman, and IR, have already been heavily utilized for chemical characterization of graphene-based materials. In particular, Raman spectroscopy has been very successful in identifying number of layers, crystal structure, defects, and doping levels. ${ }^{7,8}$ Moreover, since Raman scattering in graphene involves a double-resonance process, energy, full-width at half-maxima, and intensity of G-band and 2D-band provide indirect information about the local doping levels. ${ }^{9}$ Correlation of Raman parameters provides information about some of the electrical and chemical properties of graphene. ${ }^{10}$ Infrared
\end{abstract}

spectroscopy has also been used to probe electrical and optical properties of graphene. ${ }^{11-13}$ Recently, Basov et al. ${ }^{14,15}$ combined infrared spectroscopy and scanning probe microscopy to reveal the effects of substrates on the local electrical properties of graphene. Scanning probe microscopy techniques, such as Kelvin probe microscopy, ${ }^{16}$ scanning photocurrent microscopy, ${ }^{17}$ and electrostatic force microscopy ${ }^{18}$ have been implemented to understand local electrical and chemical properties of graphene.

Electron-based surface characterization methods are wellestablished analytical tools to analyze chemical and physical parameters of materials. Many of these methods have also been utilized to probe properties of graphene. Auger electron spectroscopy ${ }^{19}$ of graphene provides useful information about the number of layers and defect density. Wang et al. used energy loss spectroscopy to monitor bonding of lithium in intercalated graphite. ${ }^{20}$ Chemical analysis of graphene and graphene oxide films, after heat and chemical treatments, have been performed by X-ray photoelectron spectroscopy (XPS). ${ }^{21}$ For example, the binding energy of $\mathrm{C} 1 \mathrm{~s}$ can provide insight about the interaction between graphene and the underlying

Received: February 6, 2013

Accepted: March 16, 2013

Published: March 17, 2013 
(a)

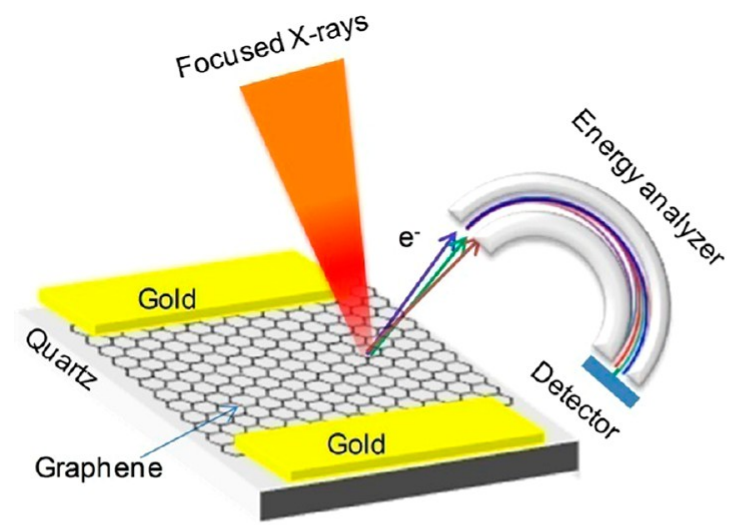

(b)

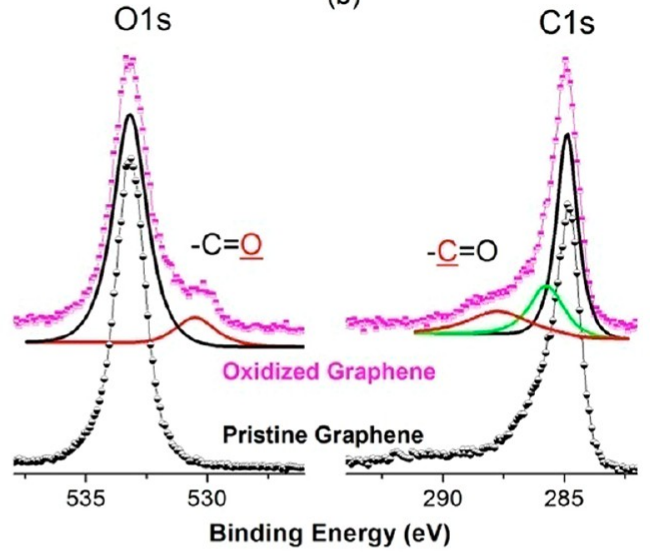

(c)

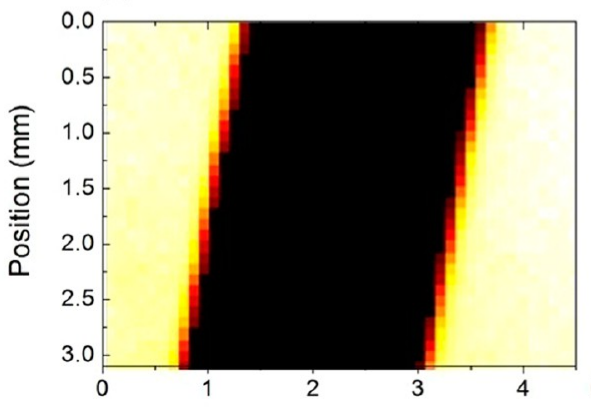

(d)

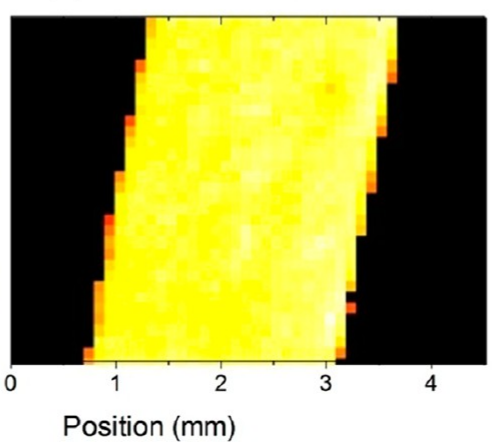

(e)

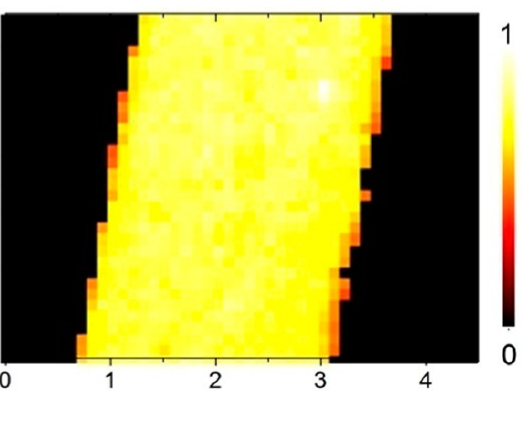

Figure 1. (a) Schematic representation of the experimental setup used for X-ray photoelectron spectroscopy on graphene. A microfocused X-ray beam with a $30 \mu \mathrm{m}$ spot size is scanned along the graphene layer between two gold electrodes. The distance between the electrodes is $1.5 \mathrm{~mm}$. The beam is scanned at $100 \mu \mathrm{m}$ steps. (b) XPS spectra of slightly oxidized and pristine graphene on quartz substrates. (c-e) Areal maps for each element; Au4f (electrode), C1s (graphene), and O1s (mainly of the quartz substrate) peaks.

substrate. $^{22}$ XPS has also been utilized for probing numerous chemical as well as electrical properties. ${ }^{23-35}$ In-situ electrical measurements during imaging with transmission electron microscopy provides correlation of atomic structure and electrical conductivity of graphene. ${ }^{36-38}$

One important aspect of the electron-based techniques is that they are also very susceptible to local electrical potentials created, intentionally or not, in the materials analyzed. In most cases, such potentials are due to charging, which has been an obstacle, and should be eliminated. ${ }^{39}$ However, introduction of electrical potentials as a bias can also be an experimental asset for harvesting additional electrical information in a chemically specific format. For example, we have recently shown that XPS data of devices under working conditions can be recorded. This, so named, operando XPS, traces chemical and location-specific surface potential variations across a working $\mathrm{CdS}$ based photoresitor. $^{40}$ By mapping $\mathrm{Cd} 3 \mathrm{~d}$ binding energy variations, we were able to obtain photoconductivity, electric field distribution, and identify some morphological defects. In a Sidiode, measurements of the position of the Si2p peak enabled us to separate and identify the $\mathrm{p}$ - and $\mathrm{n}$-doped regions and/or domains. ${ }^{41}$ In this letter, we extend our methodology to XPS characterization of voltage drop variations of large area singlelayer graphene, in a chemically specific fashion.

\section{EXPERIMENTAL SECTION}

We used a Thermo Fisher K-alpha electron spectrometer with a monochromatic Al $\mathrm{K} \alpha$ X-ray source $(h \nu=1486.6 \mathrm{eV})$. We slightly modified the spectrometer to apply an external voltage bias across the samples. The samples consist of large area $(1 \mathrm{~cm}$ $\times 1 \mathrm{~cm}$ ) graphene that was transfer-printed on a quartz substrate. To apply a bias voltage to the graphene layer, we fabricated two gold electrodes with a thickness of $50 \mathrm{~nm}$, using standard UV-photolithography and metallization process. The gap between the electrodes is around $1-4 \mathrm{~mm}$. The graphene samples, prior to contact transfer to the quartz substrate, were synthesized on copper foils with chemical vapor deposition. ${ }^{42}$ The copper foils were placed in a quartz chamber and heated to $1000{ }^{\circ} \mathrm{C}$ under a flow of hydrogen and argon. We annealed the foils at $1000{ }^{\circ} \mathrm{C}$ for $20 \mathrm{~min}$ before the growth. A mixture of methane and hydrogen $\left(7 \mathrm{sccm} \mathrm{CH}_{4}\right.$ and $\left.7 \mathrm{sccm} \mathrm{H}_{2}\right)$ was used as the reaction gas. The chamber pressure was kept at 300 mTorr during the growth. Stopping the flow of methane terminated the growth, and then, the chamber was cooled back to room temperature. After the growth, the graphene layers were transfer-printed to quartz substrates. ${ }^{43}$ This was accomplished by spin coating the copper foils with a thin layer of photoresist (PR, AZ5214). A flat elastomeric stamp (polydimethylsiloxane, PDMS) was placed on the PR layer, and the copper foil was etched away by $1.0 \mathrm{M}$ ferric chloride solution. After the etching process, the PR layer with graphene remains on the PDMS stamp. The stamp was then applied on quartz substrates and heated to $80{ }^{\circ} \mathrm{C}$ to release the PR. After removing the stamp, the PR layer was removed by dissolving in acetone. We used Raman spectroscopy to evaluate the quality and uniformity of the graphene samples on quartz substrates. 

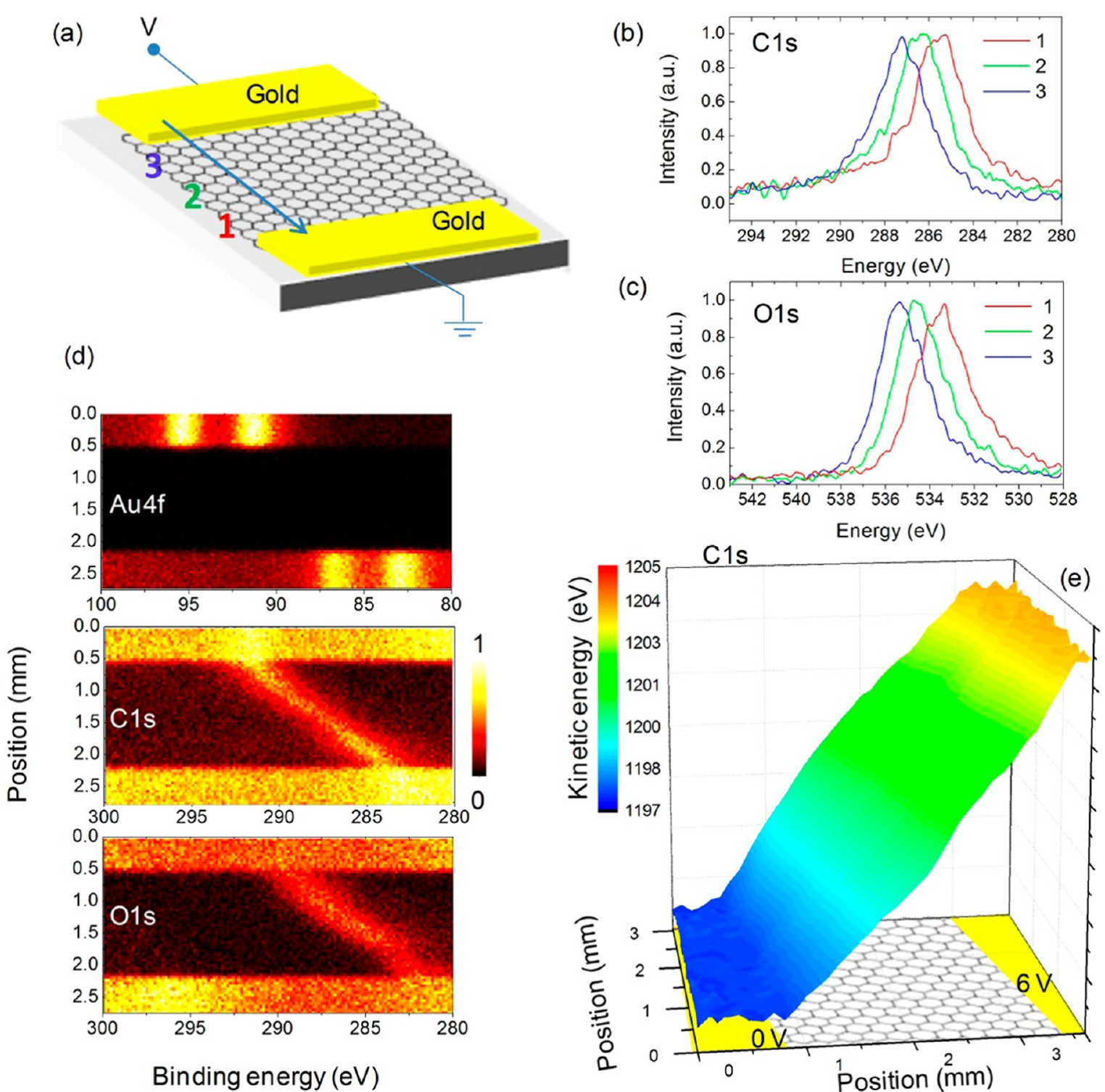

Figure 2. (a) Schematic representation of a graphene device under a voltage bias used for probing voltage drop on graphene using XPS. We ground one of the electrodes and apply $+6 \mathrm{~V}$ external voltage bias to the other electrode. ( $\mathrm{b}$ and $\mathrm{c}$ ) $\mathrm{C} 1 \mathrm{~s}$ and O1s region of the XPS spectrum of graphene on $\mathrm{SiO}_{2}$ substrate recorded at three different points between the electrodes. (d) False color contour plot of XPS line scan spectra for Au4f $\mathrm{f}_{7 / 2}$, C1s, and O1s regions. (e) 3D areal map for C1s kinetic energy of graphene in the channel between the electrodes.

The line width of $2 \mathrm{D}$ peak and the intensity ratio of $2 \mathrm{D}$ to $\mathrm{G}$ bands are $32 \mathrm{~cm}^{-1}$ and 2.4 , respectively. To oxidize the graphene layers, we exposed the samples to mild oxygen plasma ( $5 \mathrm{~W}$ RF power with $20 \mathrm{sccm}$ flow of $\mathrm{O}_{2}$ ) in a reactive ion etching system. After $2 \mathrm{~s}$ of oxidation, the resistance of the device increased from $300 \Omega$ to $1.2 \mathrm{k} \Omega$. We also measured the Raman spectra of the oxidized graphene. After the oxidation, the intensity of the $2 \mathrm{D}$ band decreased and that of the $\mathrm{D}$ band increased. The intensity ratios of $2 \mathrm{D} / \mathrm{G}$ and $\mathrm{D} / \mathrm{G}$ were around 1.0 and 1.2, respectively. Raman spectra of the pristine and oxidized graphene samples are given in the Supporting Information. $^{44}$

\section{RESULTS AND DISCUSSIONS}

Conventional XPS analysis together with elemental maps provide detailed bonding information for both pristine graphene as well as its slightly oxidized form(s), as was done for our samples shown in Figure 1, where both the oxidized
$\mathrm{C} 1 \mathrm{~s}$ and the corresponding O1s peaks appear as well-separated peaks. We go one step further and apply a voltage bias across the graphene layer lying between the two gold electrodes, during the acquisition of XPS data. By monitoring the spatial variation of the measured kinetic energies of the emitted $\mathrm{C} 1 \mathrm{~s}$ and O1s photoelectrons, we are able to map the voltage variations in the graphene layer in a chemically specific fashion. In addition to the value obtained from Einstein's equation (K.E. $=h \nu-$ B.E. $+\Phi)$, the measured kinetic energy of the emitted photoelectrons is now affected by the local electrostatic interactions, charge density, and external voltage bias. The surface potentials can be obtained from the shifts in the measured binding/kinetic energy at a precision of $0.05 \mathrm{eV}$ or better.

Figure $2 \mathrm{a}$ shows the schematic representation of the experiential setup. $\mathrm{A}+6 \mathrm{~V}$ bias was applied between the gold electrodes, and $\mathrm{Au} 4 \mathrm{f}, \mathrm{C} 1 \mathrm{~s}$, and $\mathrm{O} 1 \mathrm{~s}$ peaks were recorded in the snapshot mode, with an X-ray spot size of 30 and $100 \mu \mathrm{m}$ steps 

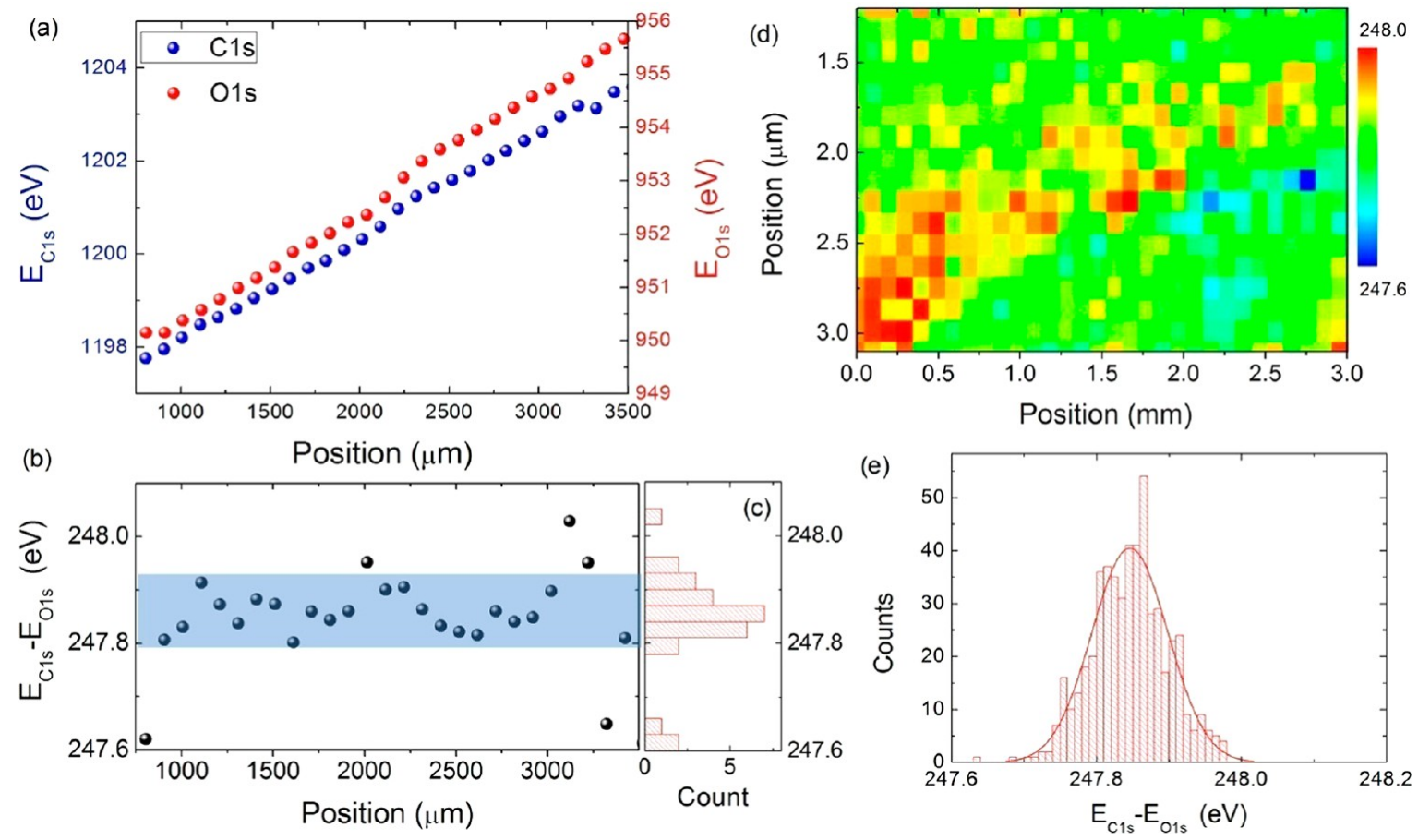

Figure 3. (a) Variation of measured kinetic energy of $\mathrm{C} 1 \mathrm{~s}$ and $\mathrm{O} 1 \mathrm{~s}$ as a function of the position between the gold electrodes. (b) Difference between the measured kinetic energy of $\mathrm{C} 1 \mathrm{~s}$ and O1s. (c) Histogram of the distribution of the kinetic energy difference for the line scan. (d) False color map of the areal scan of kinetic energy difference of $\mathrm{Cls}$ and $\mathrm{O} 1 \mathrm{~s}$ in the channel area between the electrodes. (e) Histogram of kinetic energy difference for the areal map. The standard deviation of the histogram is $0.05 \mathrm{eV}$.

over an area of $4 \times 4 \mathrm{~mm}$, including the electrodes. The resulting data set is immense and can be converted to areal maps and line-scans for each element; Au4f (electrode), C1s (graphene), and O1s (mainly of the quartz substrate) peaks are shown in Figure $2 b$ at three chosen points. As can be gathered from the figure, their peak positions vary linearly with respect to the voltage drop across the device. The surprising fact is that the O1s of the substrate faithfully follows the C1s of the graphene. In Figure 2d, Au4f, C1s, and O1s spectra along the designated line-scan is displayed, all of which exhibit a smooth resistive voltage drop across the electrodes, as is also confirmed in Figure $2 \mathrm{e}$ by the false-color areal image of the $\mathrm{C} 1 \mathrm{~s}$ peak positions.

The information content of the displayed data is very rich and can be used to extract other properties. For example, the measured $6.00 \pm 0.05 \mathrm{eV}$ binding energy difference between the Au4f peaks on the two electrodes matches exactly the applied $+6.00 \mathrm{~V}$ bias and reveals to us that no significant contact resistances exist within our experimental setup. The $\mathrm{C} 1 \mathrm{~s}$ peak also exhibits a $6.00 \pm 0.08 \mathrm{eV}$ binding energy difference. Moreover, the measured binding energy difference of $200.75 \pm 0.08 \mathrm{eV}$ between the $\mathrm{Au}_{4} \mathrm{f}_{7 / 2}$ (84.00) and $\mathrm{C} 1 \mathrm{~s}$ (284.75) peaks at both electrodes signals the absence of any measurable contact potentials between the gold electrodes and our graphene sample over as large a contact distance as 3-4 mm. ${ }^{15}$ As mentioned above, the O1s peak of the quartz substrate follows the voltage variations without the need of flood-gun neutralization. The presence of graphene provides equipotential surfaces across the device which prevents charging of the dielectric substrate. However, as shown in Figure $3 a$ and $b$, the binding energy difference between the $C 1 s$ and the O1s exhibits a fluctuation of $0.05 \mathrm{eV}$ about the mean value of $247.9 \mathrm{eV}$, which matches exactly the tabulated binding energy difference. ${ }^{39}$ The areal map of the binding energy variation and its histogram are given in Figure $3 \mathrm{~d}$ and e, respectively. The gap between the graphene and substrate, local multilayer flakes, and/or the local conductivity created by the focused X-rays could cause the variations/fluctuations of the binding energy difference between the $\mathrm{C} 1 \mathrm{~s}$ and the O1s. Even though the exact mechanism is unclear at this point, as will be shown below, such measurements can reveal information about structural and/or morphological defects of the graphene layer.

In Figure 4, we display similar spectral features of the same graphene sample after oxidation, where the voltage drop variations are no longer smooth throughout the sample area, due mainly to the cracks and/or morphological defects formed during the latter process. Figure $4 a$ shows a schematic representation of a crack on the graphene layer. By monitoring the voltage, we were able to locate such cracks on the graphene layer and have measured the binding energy variation of the $\mathrm{C} 1 \mathrm{~s}$ on the defective graphene layer under a voltage bias of $6 \mathrm{~V}$. Figure $4 \mathrm{~b}$ and $\mathrm{c}$ shows the peak positions of the $\mathrm{C} 1 \mathrm{~s}$ for three line scans at different positions relative to the crack. Initially the binding energy varies linearly with the position; however, as we move along the line scan on the crack, the linearity becomes perturbed and binding energy becomes constant indicating no local current is passing through the graphene. Furthermore, after the oxidation, the overall variation between the binding energies of $\mathrm{Cls}$ and $\mathrm{O} 1 \mathrm{~s}$ increased significantly. Figure $4 \mathrm{e}$ shows the measured $\mathrm{C} 1 \mathrm{~s}$ of graphene and $\mathrm{O} 1 \mathrm{~s}$ of the substrate $\left(\mathrm{SiO}_{2}\right)$ kinetic energy positions along the XPS line scan. The difference between the measured kinetic energy positions of $\mathrm{C} 1 \mathrm{~s}$ and $\mathrm{O} 1 \mathrm{~s}$ and its histogram are given in Figure $4 \mathrm{f}$ and $\mathrm{g}$, respectively. The standard deviation of the binding energy difference is significantly increased to $0.2 \mathrm{eV}$ due to the presence of cracks/defects. Note that, characterization using electrical means only would not have revealed this information about the electrical properties. Electrical measurement could 


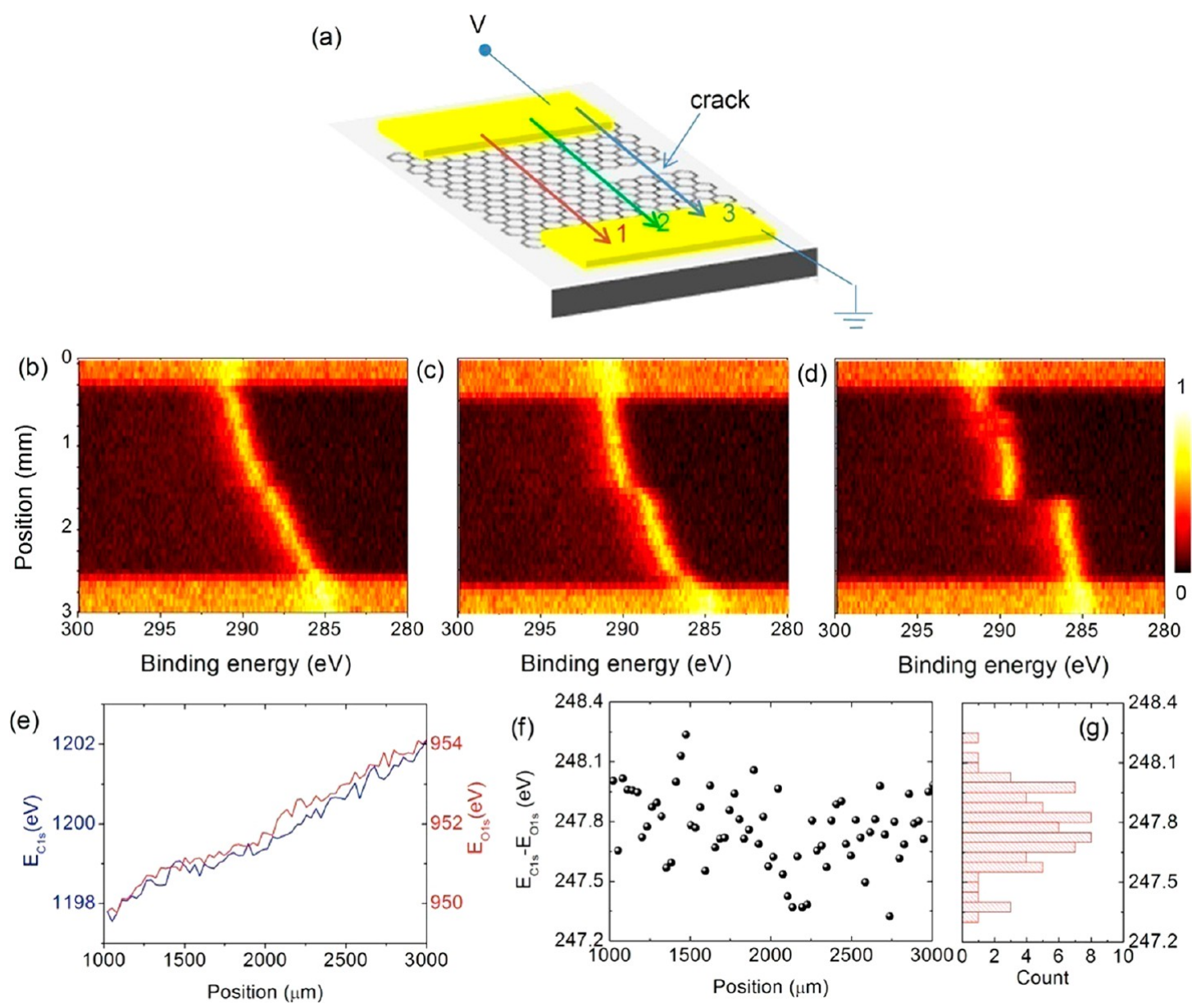

Figure 4. (a) Schematic representation of a graphene device containing a defected region (after oxidation) under a $+6 \mathrm{~V}$ bias. (b-d) Line scans of $\mathrm{C} 1 \mathrm{~s}$ region of the XPS spectra near a defected region on the graphene layer. (e) Measured $\mathrm{C} 1 \mathrm{~s}$ of graphene and $\mathrm{O} 1 \mathrm{~s}$ of the substrate $\left(\mathrm{SiO} \mathrm{O}_{2}\right)$ kinetic energy positions along the XPS line scan. (f) Difference between the measured kinetic energy of $\mathrm{C} 1 \mathrm{~s}$ and O1s. (g) Histogram of the distribution of the kinetic energy difference for the line scan. The standard deviation of the histogram is $0.2 \mathrm{eV}$.

only provide total resistance of the device. As mentioned above, after the oxidation process with mild oxygen plasma, the total resistance of the devices increased from $300 \Omega$ to $1.2 \mathrm{k} \Omega$.

\section{CONCLUSIONS}

In summary, we use X-ray photoelectron spectroscopy for characterization of voltage drop variations of large area singlelayer graphene on quartz substrates, by imposing a voltage bias across the two gold electrodes deposited on top. By monitoring the spatial variation of the kinetic energies of emitted photoelectrons, we extract voltage variations in graphene layers in a chemically specific format, which is found to be uniform across the entire layer in the pristine sample but is not uniform in the oxidized one, due to cracks and/or morphological defects created during the oxidation process. This method traces chemical and location specific surface potential variations across a working graphene device in a chemically addressed format. Furthermore, owing to high conductivity of graphene and being electron transparent, the graphene overlayer prevents charging of dielectric substrates by yielding equipotential surfaces.

\section{ASSOCIATED CONTENT}

\section{S Supporting Information}

Raman spectra of the pristine and oxidized graphene samples and histograms of areal maps. This material is available free of charge via the Internet at http://pubs.acs.org.

\section{AUTHOR INFORMATION}

\section{Corresponding Author}

*E-mail: ckocabas@fen.bilkent.edu.tr (C.K.), suzer@fen. bilkent.edu.tr (S.S.).

\section{Notes}

The authors declare no competing financial interest.

\section{REFERENCES}

(1) Novoselov, K. S.; Jiang, D.; Schedin, F.; Booth, T. J.; Khotkevich, V. V.; Morozov, S. V.; Geim, A. K. Proc Natl Acad Sci USA 2005, 102 (30), 10451-3.

(2) Novoselov, K. S.; Geim, A. K.; Morozov, S. V.; Jiang, D.; Katsnelson, M. I.; Grigorieva, I. V.; Dubonos, S. V.; Firsov, A. A. Nature 2005, 438 (7065), 197-200.

(3) Lin, Y. M.; Valdes-Garcia, A.; Han, S. J.; Farmer, D. B.; Meric, I.; Sun, Y. N.; Wu, Y. Q.; Dimitrakopoulos, C.; Grill, A.; Avouris, P.; Jenkins, K. A. Science 2011, 332 (6035), 1294-1297.

(4) Bolotin, K. I.; Sikes, K. J.; Jiang, Z.; Klima, M.; Fudenberg, G.; Hone, J.; Kim, P.; Stormer, H. L. Solid State Commun. 2008, 146 (910), 351-355. 
(5) Nair, R. R.; Blake, P.; Grigorenko, A. N.; Novoselov, K. S.; Booth, T. J.; Stauber, T.; Peres, N. M.; Geim, A. K. Science 2008, 320 (5881), 1308.

(6) Bae, S.; Kim, H.; Lee, Y.; Xu, X.; Park, J. S.; Zheng, Y.; Balakrishnan, J.; Lei, T.; Kim, H. R.; Song, Y. I.; Kim, Y. J.; Kim, K. S.; Ozyilmaz, B.; Ahn, J. H.; Hong, B. H.; Iijima, S. Nat Nanotechnol 2010, $5(8), 574-8$.

(7) Ferrari, A. C. Solid State Commun. 2007, 143 (1-2), 47-57.

(8) Dresselhaus, M. S.; Jorio, A.; Hofmann, M.; Dresselhaus, G.; Saito, R. Nano Lett. 2010, 10 (3), 751-758.

(9) Das, A.; Pisana, S.; Chakraborty, B.; Piscanec, S.; Saha, S. K.; Waghmare, U. V.; Novoselov, K. S.; Krishnamurthy, H. R.; Geim, A. K.; Ferrari, A. C.; Sood, A. K. Nat Nanotechnol 2008, 3 (4), 210-5.

(10) Kalbac, M.; Reina-Cecco, A.; Farhat, H.; Kong, J.; Kavan, L.; Dresselhaus, M. S. Acs Nano 2010, 4 (10), 6055-6063.

(11) Yan, H. G.; Xia, F. N.; Zhu, W. J.; Freitag, M.; Dimitrakopoulos, C.; Bol, A. A.; Tulevski, G.; Avouris, P. Acs Nano 2011, 5 (12), 98549860.

(12) Jiang, Z.; Henriksen, E. A.; Tung, L. C.; Wang, Y. J.; Schwartz, M. E.; Han, M. Y.; Kim, P.; Stormer, H. L. Phys. Rev. Lett. 2007, 98 (19), No. 197403.

(13) Acik, M.; Lee, G.; Mattevi, C.; Pirkle, A.; Wallace, R. M.; Chhowalla, M.; Cho, K.; Chabal, Y. J. Phys. Chem. C 2011, 115 (40), 19761-19781.

(14) Fei, Z.; Rodin, A. S.; Andreev, G. O.; Bao, W.; McLeod, A. S.; Wagner, M.; Zhang, L. M.; Zhao, Z.; Thiemens, M.; Dominguez, G.; Fogler, M. M.; Neto, A. H. C.; Lau, C. N.; Keilmann, F.; Basov, D. N. Nature 2012, 487 (7405), 82-85.

(15) Fei, Z.; Andreev, G. O.; Bao, W. Z.; Zhang, L. F. M.; McLeod, A. S.; Wang, C.; Stewart, M. K.; Zhao, Z.; Dominguez, G.; Thiemens, M.; Fogler, M. M.; Tauber, M. J.; Castro-Neto, A. H.; Lau, C. N.; Keilmann, F.; Basov, D. N. Nano Lett. 2011, 11 (11), 4701-4705.

(16) Yan, L.; Punckt, C.; Aksay, I. A.; Mertin, W.; Bacher, G. Nano Lett. 2011, 11 (9), 3543-9.

(17) Mueller, T.; Xia, F.; Freitag, M.; Tsang, J.; Avouris, P. Phys. Rev. B 2009, 79 (24), No. 245430.

(18) Burnett, T.; Yakimova, R.; Kazakova, O. Nano Lett. 2011, 11 (6), 2324-2328.

(19) Xu, M.; Fujita, D.; Gao, J.; Hanagata, N. ACS Nano 2010, 4 (5), 2937-45.

(20) Wang, F.; Graetz, J.; Moreno, M. S.; Ma, C.; Wu, L.; Volkov, V.; Zhu, Y. ACS Nano 2011, 5 (2), 1190-7.

(21) Yang, D.; Velamakanni, A.; Bozoklu, G.; Park, S.; Stoller, M.; Piner, R. D.; Stankovich, S.; Jung, I.; Field, D. A.; Ventrice, C. A.; Ruoff, R. S. Carbon 2009, 47 (1), 145-152.

(22) Brako, R.; Sokcevic, D.; Lazic, P.; Atodiresei, N. New J. Phys. 2010, 12.

(23) Busse, C.; Lazic, P.; Djemour, R.; Coraux, J.; Gerber, T.; Atodiresei, N.; Caciuc, V.; Brako, R.; N’Diaye, A. T.; Blugel, S.; Zegenhagen, J.; Michely, T. Phys. Rev. Lett. 2011, 107 (3), No. 36101.

(24) Chiu, P. L.; Mastrogiovanni, D. D. T.; Wei, D. G.; Louis, C.; Jeong, M.; Yu, G.; Saad, P.; Flach, C. R.; Mendelsohn, R.; Garfunkel, E.; He, H. X. J. Am. Chem. Soc. 2012, 134 (13), 5850-5856.

(25) Eckmann, A.; Felten, A.; Mishchenko, A.; Britnell, L.; Krupke, R.; Novoselov, K. S.; Casiraghi, C. Nano Lett. 2012, 12 (8), 39253930.

(26) Filleter, T.; Emtsev, K. V.; Seyller, T.; Bennewitz, R. Appl. Phys. Lett. 2008, 93 (13), No. 133117.

(27) Hammock, M. L.; Sokolov, A. N.; Stoltenberg, R. M.; Naab, B. D.; Bao, Z. A. ACS Nano 2012, 6 (4), 3100-3108.

(28) Kim, M.; Safron, N. S.; Huang, C. H.; Arnold, M. S.; Gopalan, P. Nano Lett. 2012, 12 (1), 182-187.

(29) Larciprete, R.; Lacovig, P.; Gardonio, S.; Baraldi, A.; Lizzit, S. J. Phys. Chem. C 2012, 116 (18), 9900-9908.

(30) Perera, S. D.; Mariano, R. G.; Vu, K.; Nour, N.; Seitz, O.; Chabal, Y.; Balkus, K. J. ACS Catal. 2012, 2 (6), 949-956.

(31) Prezioso, S.; Perrozzi, M.; Donarelli, M.; Bisti, F.; Santucci, S.; Palladino, L.; Nardone, M.; Treossi, E.; Palermo, V.; Ottaviano, L. Langmuir 2012, 28 (12), 5489-5495.
(32) Rana, K.; Kucukayan-Dogu, G.; Sen, H. S.; Boothroyd, C.; Gulseren, O.; Bengu, E. J. Phys. Chem. C 2012, 116 (20), 1136411369.

(33) Usachov, D.; Vilkov, O.; Gruneis, A.; Haberer, D.; Fedorov, A.; Adamchuk, V. K.; Preobrajenski, A. B.; Dudin, P.; Barinov, A.; Oehzelt, M.; Laubschat, C.; Vyalikh, D. V. Nano Lett. 2011, 11 (12), 54015407.

(34) Wang, S. N.; Wang, R.; Liu, X. F.; Wang, X. W.; Zhang, D. D.; Guo, Y. J.; Qiu, X. H. J. Phys. Chem. C 2012, 116 (19), 10702-10707.

(35) Wei, D. C.; Liu, Y. Q.; Wang, Y.; Zhang, H. L.; Huang, L. P.; Yu, G. Nano Lett. 2009, 9 (5), 1752-1758.

(36) Xu, Z.; Bando, Y.; Liu, L.; Wang, W. L.; Bai, X. D.; Golberg, D. ACS Nano 2011, 5 (6), 4401-4406.

(37) Ho, P.-H.; Yeh, Y.-C.; Wang, D.-Y.; Li, S.-S.; Chen, H.-A.; Chung, Y.-H.; Lin, C.-C.; Wang, W.-H.; Chen, C.-W. ACS Nano 2012, 6 (7), 6215-6221.

(38) Tsen, A. W.; Brown, L.; Levendorf, M. P.; Ghahari, F.; Huang, P. Y.; Havener, R. W.; Ruiz-Vargas, C. S.; Muller, D. A.; Kim, P.; Park, J. Science 2012, 336 (6085), 1143-1146.

(39) Briggs, D. S., M. P. Practical Surface Analysis: Auger and X-ray photoelectron spectroscopy, 2nd ed.; John Wiley \& Sons: Chichester, 1996.

(40) Sezen, H.; Suzer, S. Anal. Chem. 2012, 84, 2990-2994.

(41) Suzer, S. Anal. Meth.-UK 2012, 4 (11), 3527-3530.

(42) Li, X. S.; Cai, W. W.; An, J. H.; Kim, S.; Nah, J.; Yang, D. X.; Piner, R.; Velamakanni, A.; Jung, I.; Tutuc, E.; Banerjee, S. K.; Colombo, L.; Ruoff, R. S. Science 2009, 324 (5932), 1312-1314.

(43) Salihoglu, O.; Balci, S.; Kocabas, C. Appl. Phys. Lett. 2012, 100 (21), No. 213110.

(44) See the Supporting Information. 